\title{
Güneydoğu Anadolu Bölgesi'nde Gemlik Zeytin (olea aeoropea) Çeșidinde Sulamanın Peryodisite Üzerine Etkisi
}

\author{
Meral ANLAĞAN TAȘ 1 ** Abdullah Suat NACAR' Veli DEĞílRMENCi ${ }^{1}$ \\ Ebru SAKAR ${ }^{2} \quad$ PInar BAHÇECI ALSAN ${ }^{3}$ \\ 'GAP Tarımsal Araștırma Enstitüsü, Șanlıurfa \\ ${ }^{2}$ Harran Üni. Bahçe Bitkileri Bölümü, Șanlıurfa \\ ${ }^{3}$ Toprak, Gübre ve Su Kaynakları Merkez Araștırma Enstitüsü, Ankara
}

\begin{abstract}
*Sorumlu yazar e-mail (Corresponding author e-mail): meral.anlagantas@tarimorman.gov.tr Gelis tarihi (Received) : 03.05.2019

Kabul tarihi (Accepted): 28.08.2019

DOI: $10.21657 /$ topraksu. 655572
\end{abstract}

Öz

Bu araștırma, Șanlıurfa koșullarında yetiștirilen zeytin ağaçlarına farklı gün aralıklarında yapılan sulama uygulamalarının verim ve peryodisiteye etkisini tespit etmek, araștırma bölgesinde yetiștirilen zeytin bitkisi için uygun sulama programını belirlemek amacıyla, GAP Tarımsal Araștırma Enstitüsü tarafından 2010-2015 yılları arasında Șanlıurfa Büyükșehir Belediyesine bağlı Șehit Nusret Bey Fidanlığında yürütülmüștür. Deneme Konuları S1-Susuz, S2-7 gün, S3-14 gün, S4-21 gün, S5-28 gün ve S6-35 gün konularından olușmuștur.

Elde edilen araștırma sonuçları değerlendirildiğinde; ilk iki yıl ön verim olarak alınmıș, 2012 yılında sulama konularına bașlanılmıștır. Yapılan istatistiki analizler sonucu her dört yılda S4 konusu (21 gün) ilk sırada yer almıștır.S4 konusuna uygulanan sulama suyu 749 mm, bitki su tüketimi 834 mm, elde edilen verim $1198 \mathrm{~kg} / \mathrm{da}$ olmuștur.

Anahtar kelimeler : Mini spring, sulama, Șanlıurfa, zeytin

\section{The Impact of Irrigation on the Periodicity of Gemlik Olive (olea aeoropea) in Southeastern Anatolia Region}

\begin{abstract}
The research, that was supported by GAP Agricultural Research Institute, was conducted from 2010 to 2015 at the field belonged to metropolitan municipality of Sanlıurfa. The reseach goal was to clarify yield, oil quality, and their effects on periodicity for olive trees on natural conditions with different irrigation periods. Also, it aimed to identify an appropriate amount and time periods of applying water for olive trees by separeted 6 part fields as non-irrigated (S1), irrigated once of each 7 days (S2), each 14 days (S3), each 21 days (S4), each 28 days (S5), and each 35 days.

The first 2 years of the research period was evaluated as adaptation of the trees, then the field was started to separete to 6 parts and irrigate based on each research topic explained above. The results of statistical analysis showed that the highest yield was obtained about $1198 \mathrm{~kg} / \mathrm{da}$ from 54 (irrigated once of each 21 days). The amount of applied water on S4 area was about 479 mm, and evapotranspiration rate of trees was about $834 \mathrm{~mm}$.
\end{abstract}

Key words: Mini spring, olive trees, irrıgation, Șanlıurfa 


\section{Giriș}

Güneydoğu Anadolu Bölgesi tarım alanları, GAP projesi ile birlikte sulu tarıma geçmiș ve dolayısıyla geleneksel tarım anlayıșı son yıllarda yerini modern tarıma bırakmaya bașlamıștır. Bölgede sulanan alanların artmasıyla, beklenen bir sonuç olarak ürün çeșitliliği ve arazi kullanım planlamaları da değișmeye bașlamıștır.

Zeytin için gereksinim duyduğu sulama suyunun büyük bir kısmını, evapotranspirasyonun yüksek olduğu haziran, temmuz ve ağustos gibi sıcak yaz aylarında uygulamak gerekmektedir. Yıllık sulama suyu gereksinimi 600 mm civarındadır. Özellikle yaz aylarında hava sıcaklıklarının artması ve bitkinin evapotranspirasyon yoluyla așırı su kaybetmesi nedeniyle kuraklık stresinden korunmak için daha sık sulamaya intiyaç duyulur.

Periyodisitenin șiddetini azaltmak için uygulanacak kültürel önlemlerden en önemlisi sulamadır. Zeytin yetiștiriciliğinde karșılașılan en önemli sorunlardan bir tanesi periyodisitedir. Ağacın bir yıl az, ertesi yıl fazla miktarda ürün vermesi gerek iç piyasa arzında ve gerekse yurt dıșına yapılan zeytin inracatında büyük sorunlara neden olmaktadır. Periyodisite nedeni ile zeytin üretimimiz \% 50' den fazla düșüș göstermektedir. Periyodisite sorununun çözümü zeytin yetiștiriciliğine büyük katkılar sağlayacaktır. Zeytin yetiștiriciliğinde yok yılındaki üretimi önemli miktarda artırmak ülke ekonomisine büyük katkı sağlayacaktır. Ayrıca su kaynaklarımızın tasarruflu kullanımı da söz konusu olacaktır.

Denemede Gemlik zeytin çeșidinden olușan bir zeytin bahçesi kullanılmıștır. Bahçede mini sprink sulama sistemi ile $0,7,14,21,28$ ve 35'șer gün aralıklarında tarla kapasitesine göre sulama yapıımıștır. Belli gün aralıklarında yapılan sulamaların periyodisite etkileri belirlenmiștir. Bu sayede sulamanın periyodisite üzerine etkileri ile zeytinyağı kalitesi üzerine etkileri ortaya konmuștur. Bunun sonucunda ise kısıntılı su uygulaması ile su tasarrufu sağlanmıș, periyodisitenin olușum mekanizması belirlenmiș ve sulamanın periyodisite ve zeytinyağı kalitesi üzerine etkileri incelenmiștir. Ayrıca Güneydoğu Anadolu Bölgesi koșullarında zeytinin su tüketimi de saptanmıștır.

\section{MATERYAL VE YÖNTEM}

\section{Araștırma yeri}

Araștırma; Șanlıurfa-Mardin karayolu üzerinde, Șanlıurfa Büyükșehir Belediyesine bağlı Șehit Nusret Bey fidanlığındaki zeytin bahçesinde yürütülmüștür. Gemlik zeytin çeșidinden olușan bahçe de ağaçlar denemenin ilk yılında 10 yașında olup, 6×6 m aralık mesafede dikilmișlerdir.

\section{Toprak özellikleri}

Denemenin yürütüldüğü bahçe Sırrın Toprak Serisinde yer almaktadır. Harran Ovasının kuzeyinde çamur akıntılarından olușmuș düz, düze yakın, çok derin A, B, C horizonlu olup, tüm profil kil tekstürlüdür. Tüm profil çok kireçlidir. Sırrın serisi topraklarında $\mathrm{pH}$ 7.2-7.5 arasında olup, organik madde içeriği düșük, Katyon Değișim Kapasiteleri yüksektir. Organik madde içeriği așağılara doğru azalmakta \%0.4-0.9 arasında değișmektedir (Dinç vd., 1988).

\section{İklim özellikleri}

Șanlıurfa, Güneydoğu Anadolu iklim bölgesine dahil olmakla beraber Akdeniz ikliminin etkisi altındadır. Yazlar sıcak ve kurak, kıșlar ise ılık olan bir iklim özelliği göstermektedir. Güneyden kuzeye gittikçe yağıș miktarı artmaktadır. 19 Yıllık rasat değerlerine göre yıllık ortalama yağıșın mevsimlere dağııș miktarı kıș \%53, ilkbahar \%28, yaz \%1, sonbahar \%18'tür. Yıllık ortalama yağıș $384 \mathrm{~mm}$. civarındadır. Yıllık ortalama sıcaklık $17.1^{\circ} \mathrm{C}$ civarındadır. En yüksek sıcaklık $46.8^{\circ} \mathrm{C}$, en düșük sıcaklık -16.8 ${ }^{\circ} \mathrm{C}$ olarak saptanmıștır. Illk don 30 Ekim, son don 27 Nisan'da görülmüștür. Ortalama nisbi nem \%49'dur. Nisbi nem \%31 ile Temmuz ayında en düșük, \%69 ile Aralık ayında en yüksek değerine ulașmaktadır (Anonim, 2016).

\section{Araștırmanın yürütüldüğü zeytin çeșidi}

Gemlik Zeytini Marmara Bölgesinin zeytin ağaçlarının büyük bir kısmını olușturur. Özel bir grubu olușturan Gemlik Zeytinleri her yıl düzenli olarak meyve verir. Zeytinin en belirgin özelliği renginin koyu siyah olması ve etinin çekirdekten kolayca ayrılabilmesidir. Meyve ve çekirdekleri orta irilikte olup \%29.9 oranında yağ içerir. Gemlik zeytini için Trilye, Kıvırcık, Kaplık, Kara gibi isimlerde kullanilır (Anonim, 2010).

\section{Su kaynağı ve sulama sistemi unsurları}

Sulama ișlemine ilkbaharda elverișli nem \%60'a düștüğüzaman bașlanmıștır. İlksulamadan itibaren 
tüm parsellerin 0-90 cm toprak derinliğindeki eksik nemi tarla kapasitesine çıkarıldıktan sonra konulu su uygulamalarına bașlanmıștır. Sulama programı; 0-35 gün aralığında tüm sulamalarda toprak profilinin $90 \mathrm{~cm}$ derinliğindeki eksik nem tarla kapasitesine çıkarılarak parsel alanı ve 0.40 örtü yüzdesi ile düzeltildikten sonra su sayacı denetiminde uygulanmıștır. Topraktaki mevcut nem düzeyi 0-30, 30-60, 60-90 ve $90-120 \mathrm{~cm}$ toprak katmanlarından toprak örnekleri alınarak, gravimetrik yöntemle belirlenmiștir.

Denemede mini sprink yağmurlama sistemi kullanıımıștır. Yapılan infiltrasyon testi sonucuna göre bașlık debisi 200 lt/h, ıslatma çapı 6 m seçilmiștir.

\section{Tarla deneme metodu ve parsel ölçüleri}

Deneme; Tesadüf Blokları Deneme Desenine göre ve 3 tekerrürlü olarak yürütülmüștür.

\section{Parsel ölçüleri}

Parseller $18 \mathrm{~m} \times 6 \mathrm{~m}$ boyutunda, her bir parselde 3 adet zeytin ağacı bulunmakta, her bir parseldeki toprak nemi ölçümleri 6×6 metrelik alanda 1 ağaç üzerinde yürütülmüștür. Sistem içerisinde her konu için bir vana konulmuș ve konu sulamaları bu vanalardan kontrol edilmiștir.

\section{Konular}

S1-Susuz, S2- 7 günde bir sulanan konu, S3- 14 günde bir sulanan konu, S4- 21 günde bir sulanan konu, S5-28 günde bir sulanan konu, S6- 35 günde bir sulanan konu

\section{Sulama suyu ve bitki su tüketiminin hesaplanması}

Zeytin ağaçları, ilkbaharda bitki kök bölgesindeki elverișli kapasite \%60'a düștüğünde tüm ağaçlara ilk su eșit olarak verilmiștir. Hasattan 3 hafta öncesine kadar sulama ișlemine devam edilmiștir. Sulamalardan önce toprak nem düzeyi saptanarak $120 \mathrm{~cm}$ derinliğindeki toprak nemi $0-30 \mathrm{~cm}$., 30$60 \mathrm{~cm}, 60-90 \mathrm{~cm}$ ve $90-120 \mathrm{~cm}$ toprak örnekleri alınarak 0-90 cm toprak katmanındaki nem düzeyi tarla kapasitesine getirilmiștir. Sulama suyu miktarı așağıdaki eșitlikle hesaplanmıștır.

$\mathrm{I}=$ Ofc-Qc, Qc = Sulamadan önceki mevcut nem $(\mathrm{mm})$, Ofc $=$ Tarla kapasitesi $(\mathrm{mm})$

Parsellere uygulanacak sulama suyu deneme yerinde su sayacı ile ölçülmüștür.

Toprak nem ölçümleri ve bitki su tüketiminin belirlenmesi
Topraktaki nem içerikleri 0-120 cm toprak katmanı dikkate alınarak her 30 cm' lik katmanlardan alınacak örneklerde gravimetrik olarak saptanmıștır.

Bitki su tüketiminin hesaplanmasında su bütçesi eșitliği kullanılmıștır (James, 1988)

$$
\begin{aligned}
& \text { Et = I+P }+\mathrm{Cr} \pm \mathrm{Dr}-\mathrm{Rf} \pm \Delta \mathrm{m} \\
& \text { Eșitlikte; } \\
& \text { Et = Bitki su tüketimi ( } \mathrm{mm} \text { ) } \\
& \mathrm{I}=\text { Sulama suyu ( } \mathrm{mm} \text { ) } \\
& \mathrm{P}=\text { Yağıș ( mm ) } \\
& \mathrm{Cr}=\text { Kapillar ( Kılcal ) yükselme ( mm ) } \\
& \mathrm{Dr}=\text { Derine sızma kaybı ( mm ) } \\
& \mathrm{Rf}=\text { Yüzey akıș kaybı ( mm ) } \\
& \Delta \mathrm{m}=\text { Profildeki nem değișimi ( mm ) } \\
& \mathrm{Cr} \text { değeri= Kapilar beslenmenin olma intimali }
\end{aligned}
$$
azdır. Bu nedenle K değeri "0" kabul edilmiștir.

Dr değeri= Parsellere mevcut nemi tarla kapasitesine getirecek kadar sulama suyu uygulandığından derine sızma yok ("0" ) kabul edilmiștir.

Rf değeri= Yüzey akıșı olmamıștır. Bu nedenle $R$ değeri de "0" kabul edilmiștir.

\section{Toprakta yapılan gözlem, ölçme ve analizler}

Deneme alanı topraklarının temel fiziksel ve kimyasal özelliklerini saptamak amacıyla 0-30, 3060, 60-90,90-120 cm derinliklerde bozulmuș ve bozulmamıș toprak örnekleri alınmıștır. Toprakların hacim ağırlıklarının saptanmasında; bozulmamıș toprak örnekleri kullanılmıștır, Bu amaçla deneme alanında açılan profil çukurlarından yararlanılmıștır, Tarla kapasitesi ve solma noktası; basınçlı plaka aleti kullanılarak, toprak örneklerinin sırasıyla $1 / 3$ ve 15 atmosferde tuttukları nem miktarının saptanması ile bulunmuștur.

- Toprak analizleri Tüzüner (1990)'da verilen esaslardan yararlanılarak,

- pH; cam elektrodlu Beckman pH metresi ile satürasyon çamurunda,

- EC; kondaktivite aletiyle saturasyon ekstraktının elektriksel iletkenliği ölçülerek,

- Kireç (\%) : Scheibler kalsimetresi ile toprağın 1/3'lük $\mathrm{HCl}$ ile muamele edilmesi sonucu olușan $\mathrm{CO}_{2}$ 'in hacmi ölçülerek, 
- Toprak bünyesi; Hidrometre Yöntemi ile;

-Organik madde, Walkley Black Yöntemine göre;

- Yarayıșlı fosfor, Olsen metoduyla kolorimetrik olarak;

- Yarayıșlı potasyum, amonyum asetat çözeltisinden geçen potasyum miktarı fleymfotometrede okunarak,

- Sulamada kullanılan suyun, sulamaya uygunluk yönünden sınıfını belirlemek için Tüzüner (1990)'da verilen analiz yöntemleri ve sınıflandırma diyagramları kullanılmıștır,

Çizelge 1. Deneme yeri topraklarının bazı fiziksel özellikleri Table 1. Some physical properties of soil

\begin{tabular}{|c|c|c|c|c|c|c|c|}
\hline \multirow{2}{*}{$\begin{array}{l}\text { Derinlik } \\
(\mathrm{cm})\end{array}$} & \multicolumn{3}{|c|}{ Bünye } & \multirow{2}{*}{$\begin{array}{c}\text { Bünye } \\
\text { sınıfı }\end{array}$} & \multirow{2}{*}{$\begin{array}{l}\text { Hacim } \\
\text { ağırlığı } \\
\left(\mathrm{g} / \mathrm{cm}^{3}\right)\end{array}$} & \multicolumn{2}{|c|}{$\%$ PW } \\
\hline & $\begin{array}{c}\text { kum } \\
(\%)\end{array}$ & $\begin{array}{c}\text { kil } \\
(\%)\end{array}$ & $\begin{array}{l}\text { Silt } \\
(\%)\end{array}$ & & & TK & SN \\
\hline & 34 & 48 & & & & & \\
\hline $30-$ & 28 & 56 & 16 & & & & \\
\hline $60-c$ & 28 & 56 & 16 & $C$ & 1.3 & 36.82 & 23. \\
\hline $90-120$ & 28 & 50 & 22 & C & 1.33 & 33.13 & 20.57 \\
\hline
\end{tabular}

Çizelge 2. Deneme yeri topraklarının bazı kimyasal özellikleri Table 2. Some chemical properties of soil

\begin{tabular}{|c|c|c|c|c|c|c|}
\hline \multirow{2}{*}{$\begin{array}{c}\text { Derinlik } \\
(\mathrm{cm})\end{array}$} & \multirow{2}{*}{$\begin{array}{c}\text { Su ile } \\
\text { doymuș } \\
\text { toprakta } \\
\text { pH }\end{array}$} & \multirow{2}{*}{$\begin{array}{c}E . C \\
(d S / m)\end{array}$} & \multirow{2}{*}{$\begin{array}{c}\text { Kireç } \\
\mathrm{CaCO}_{3} \\
(\%)\end{array}$} & \multicolumn{2}{|c|}{$\begin{array}{c}\text { Bitkilere yarayıșlı } \\
\text { (Kg/da) }\end{array}$} & \multirow{2}{*}{$\begin{array}{l}\text { Org. } \\
\text { madde } \\
(\%)^{*}\end{array}$} \\
\hline & & & & $\begin{array}{l}\text { Fosfor } \\
\left(\mathrm{P}_{2} \mathrm{O}_{5}\right)^{*}\end{array}$ & $\begin{array}{c}\text { Potas } \\
\left(\mathrm{K}_{2} \mathrm{O}\right)^{*}\end{array}$ & \\
\hline $0-30$ & 7.58 & 0.84 & 26.6 & 2.54 & 110.10 & 1.48 \\
\hline $30-60$ & 7.18 & 0.58 & 27.3 & 2.13 & 127.40 & 2.41 \\
\hline $60-90$ & 7.53 & 0.78 & 27.3 & & & \\
\hline $90-120$ & 7.47 & 0.52 & 30.0 & & & \\
\hline
\end{tabular}

* $=$ verimlilik analizleri 0-20,20-40 cm'de yapıımıștır.

Çizelge 1 ' İn incelenmesinden görüleceği üzere araștırmanın yürütüldüğü topraklar; killi bünyeye sahip, hafif alkali, tuzsuz ve çok fazla kireçlidir. Çizelge 2'nin incelenmesinden görüleceği üzere ise orta derecede fosfor içeren, potasyumu yüksek, organik maddece fakirdir.

\section{Yapılan tarımsal ișlemler}

\section{Dikim}

Proje Șanlıurfa III Özel İdaresine bağı Șehit Nusret Bey fidanlığında 2002 yııında Gemlik çeșidiyle tesis edilen zeytin bahçesinde yürütülmüș olup, 2008 yılı grup kararları doğrultusunda 2 yıl ön verim alındıktan sonra sulama konularına geçilmiștir.

\section{Sulama}

Sulama ișlemine ilkbaharda elverișli nem \%60'a düștüğü zaman bașlanmıștır. Illk sulamadan itibaren tüm parsellerin $0-90 \mathrm{~cm}$. toprak derinliğindeki eksik nemi tarla kapasitesine çıkarıldıktan sonra konulu su uygulamalarına bașlanmıștır. Sulama programı; 0-35 gün aralığında tüm sulamalarda toprak profilinin 90 $\mathrm{cm}$ derinliğindeki eksik nem tarla kapasitesine çıkarılarak parsel alanı ve 0.40 örtü yüzdesi ile düzeltildikten sonra litre olarak su sayacı denetiminde uygulanmıștır. Topraktaki mevcut nem düzeyi 0-30, 30-60, 60-90 ve 90-120 cm toprak katmanlarından toprak örnekleri alınarak, gravimetrik yöntemle belirlenmiștir.

Denemede mini sprink yağmurlama sistemi kullanılmıștır. Yapılan infiltrasyon testi sonucuna göre bașlık debisi 200 It/h, Islatma çapı 6 m seçilmiștir.

\section{Gübreleme}

Azotlu gübre olarak Amonyum Sülfat (\%21N), potasyumlu gübre olarak Potasyum Sülfat $1 \% 50$ $\mathrm{K}_{2} \mathrm{O}$ ) ve $\% 42^{\prime}$ lik fosfor içeren süper fosfat gübreleri verilmiștir. Ağaç bașına $0.9 \mathrm{~kg} \mathrm{~N}$ gelecek șekilde verilen azotlu gübrenin 1/3' ü sonbaharda, 2/3' ü de șubat-mart ayları içerisinde verilmiștir. Ayrıca $\% 42^{\prime}$ lik fosfor içeren süper fosfattan $0.4 \mathrm{~kg} \mathrm{P}$, potasyum sülfattan da yine ağaç bașına $0.4 \mathrm{~kg} \mathrm{~K}$ olacak șekilde sonbaharda verilmiștir.

\section{Tarımsal mücadele ve bakım}

Sulamalar bașladıktan sonra yabancı otlar bellenerek alınmıștır. Deneme suresince ağaçlar budanmıș ve budamalardan sonra soğuktan ve hastalıktan etkilenmemeleri için \%2'lik bordo bulamacı uygulanmıștır.

\section{Hasat}

Zeytin meyveleri yeterli olgunluk ve renge ulaștığında hasat edilmiștir. S2 konusu (7 günde bir sulama) erken olgunlaștığından 6.11.2012, 6.11.2013, 01.11 .2014 ve 05.11.2015 tarihlerinde hasat edilerek ağaç bașına verimler tartılarak kaydedilmiștir. Ön verim alınan yıllarda olgunlașma geç olmuștur. Sulama konularının uygulandığı yıllarda olgunlașma erken olmuștur.

Araștırmada yıllara göre fenolojik gözlem ve bazı tarımsal ișlemlerle ilgili tarihler Çizelge 3'de verilmiștir. 
Çizelge 3. Araștırma yıllarında yapılan bazı ișlem ve gözlem tarihleri

Table 3. Dates of some operations and observations made during the research

\begin{tabular}{lccccccc}
\hline \multirow{2}{*}{ Gözlemler } & \multicolumn{7}{c}{ Ylllar } \\
\cline { 2 - 7 } & 2009 & 2010 & 2011 & 2012 & 2013 & 2014 & 2015 \\
\hline Çiçeklenme bașlangıç tarihi & 01.05. & 29.04 & 03.05. & 24.04. & 20.04. & 19.04. & 21.04. \\
Meyve tutumu & 05.06. & 30.05. & 10.06. & 19.05. & 14.05. & 13.05. & 20.05. \\
Yeșil olum dönemi tarihi & 12.08. & 12.08. & 18.08. & 13.08. & 03.08. & 05.08. & 10.08. \\
Siyah olum dönemi tarihi & 19.10. & 19.10. & 19.10. & 15.10. & 05.10. & 01.10. & 05.10. \\
Hasat tarihi & 26.11. & 26.11. & 30.11. & 15.11. & 18.11. & 10.11. & 10.11. \\
\hline
\end{tabular}

\section{BULGULAR ve TARTIȘMA}

\section{Sulama suyu miktarı ve su tüketimi}

Denemenin yürütüldüğü yıllarda konulara verilen sulama suyu miktarları Çizelge 4'de ve su tüketimi değerleri de Çizelge 5' de verilmiștir.

Deneme konularının sulama aralıkları farkı olduğundan, sulama sayıları da farklı olmuștur. Sulama sayısı olarak 2014 yılında S2 konusuna 32 sulama uygulanmıștır. Sulama konularına 2014 yılında yağıș az olduğundan erken bașlanılmıștır. Yıl ortalamalarına göre uygulanan sulama suyu

Çizelge 4. Konulara uygulanan yıllık toplam sulama sayısı ve sulama suyu suyu miktarları, (mm)

Table 4. Total number of irrigation per year and amounts of irrigation water, $(\mathrm{mm})$

\begin{tabular}{cccccccc}
\hline & Ylllar & \multicolumn{7}{c}{ Konular } \\
\cline { 3 - 8 } & & S1 & S2 & S3 & S4 & S5 & S6 \\
\hline \multirow{5}{*}{ Sulama } & 2012 & - & 25 & 13 & 9 & 7 & 5 \\
sayısı & 2013 & - & 29 & 15 & 10 & 8 & 6 \\
& 2014 & - & 32 & 16 & 11 & 8 & 7 \\
& 2015 & - & 27 & 13 & 9 & 7 & 6 \\
\hline \multirow{5}{*}{ Sulama } & Ort & & 28 & 14 & 10 & 8 & 6 \\
\hline suyu & 2012 & - & 1207 & 885 & 704 & 539 & 427 \\
& 2013 & & 1309 & 1008 & 765 & 626 & 514 \\
& 2015 & & 1553 & 1086 & 813 & 609 & 569 \\
& Ort & & 1404 & 881 & 712 & 558 & 472 \\
\hline
\end{tabular}

Çizelge 5. Konuların mevsimlik su tüketimleri, $(\mathrm{mm})$

Table 5. Seasonal water consumption of subjects, $(\mathrm{mm})$

\begin{tabular}{|c|c|c|c|c|c|c|c|}
\hline & \multirow{2}{*}{ Yıllar } & \multicolumn{6}{|c|}{ Konular } \\
\hline & & S1 & S2 & S3 & S4 & S5 & S6 \\
\hline \multirow{5}{*}{$\begin{array}{c}\text { Su } \\
\text { tüketimi }\end{array}$} & 2012 & 218 & 1291 & 921 & 732 & 551 & 450 \\
\hline & 2013 & 234 & 1509 & 1064 & 813 & 652 & 641 \\
\hline & 2014 & 346 & 1624 & 1186 & 946 & 698 & 672 \\
\hline & 2015 & 294 & 1472 & 951 & 846 & 700 & 579 \\
\hline & Ort & 273 & 1474 & 1031 & 834 & 650 & 586 \\
\hline
\end{tabular}

1368- 496 mm arasında değișmiștir. Sulama sayısı ortalamaları S2 konusunda 28, S6 konusunda 6 olmuștur. Konuların ortalama su tüketim değerleri en düșük sulanmayan konuda 273 mm olurken en yüksek 7 günde bir sulanan konuda 1474 mm olmuștur.

Yıllara göre elde edilen verimlerin toplu analizinin yapılıp yapılamayacağı Khi-kare (Hesaplanan $X^{2}=14.22, \mathrm{SD}=3$ den tablo $X^{2}$ değerleri \%5 için 7.81 ve \%1 için 11.34) homojenlik testine göre kontrol edilmiștir. Yıllara göre hata varyanslarının homojen olmadığı görülmüștür. Bunun sonucu olarak yıl yıl değerlendirilmiștir. Verimler 2012 yılında 686880 kg/da, 2013 yılında $781-1078$ kg/da, 2014 yılında 477- $991 \mathrm{~kg} / \mathrm{da}, 2015$ yılında 725-1855 kg/da arasında değișmiștir (Çizelge 6). Dört yılın ortalama verimleri $667-1198 \mathrm{~kg} / \mathrm{da}$ arasında değișmiștir. S1 konusu 667 kg/da en düșük, S4 konusu 1198 kg/da en yüksek verim vermiștir. Her 4 yılda S4 (21 gün) konusu en yüksek verimle birinci grupta yer almıștır.

Faci vd. (2002), Romero vd. (2002), Andria ve Morelli (2002) çalıșmalarında sulamayla meyve veriminin arttığını belirtmișlerdir. Bizim çalıșmamız ile de paralellik göstermektedir.

Çizelge $\mathbf{6}$. Deneme yıllarında konuların ortalama verimleri, (kg/da)

Table $\mathbf{6}$. Average yields of the subjects by years, (kg/da)

\begin{tabular}{|c|c|c|c|c|c|c|c|}
\hline & \multicolumn{6}{|c|}{ Konular } \\
\hline & & S1 & $S 2$ & S3 & S4 & 55 & 56 \\
\hline \multirow{5}{*}{$\begin{array}{l}\text { Verim } \\
\text { Kg/da }\end{array}$} & 2012 & 686 & 748 & 714 & 880 & 814 & 777 \\
\hline & 2013 & $781 \mathrm{~b}$ & 1078a & 1073a & 1065a & $987 a$ & $951 a$ \\
\hline & 2014 & $477 c$ & $707 b$ & 739b & 991 a & $800 b$ & $708 b$ \\
\hline & 2015 & $725 e$ & $1434 b$ & $1388 \mathrm{bc}$ & 1855a & $1307 c$ & $875 d$ \\
\hline & Ort & 667 & 992 & 979 & 1198 & 977 & 828 \\
\hline
\end{tabular}




\section{SONUÇLAR}

Bu çalıșma, Güneydoğu Anadolu Bölgesi'nde Gemlik Zeytin (Olea aeoropea) çeșidinde sulamanın peryodisite ve yağ kalitesi üzerine etkisinin belirlenmesi ve araștırma bölgesinde uygulanabilir sulama programlarının olușturulması amaçlanmıștır. Araștırma Șanlıurfa İ Özel İdaresine bağlı Șehit Nusret Bey fidanlığında 2002 yılında Gemlik çeșidiyle tesis edilen zeytin bahçesinde yürütülmüș olup, 2 yıl (2010-2011) ön verim alındıktan sonra sulama konularına geçilmiștir. 2012-2015 yılları arasında sulama konuları uygulanmıștır. Deneme konuları; S1: susuz, S2:7 gün, $\$ 3: 14$ gün, $\$ 4: 21$ gün, $\$ 5: 28$ gün ve $\$ 6$ : 35 gün aralıklarını içeren sulama konularından olușmaktadır.

Yapılan istatistiki analizlerde 2012 yılı haricinde diğer yıllarda konular arasında fark çıkmıștır. 2012 yılında verim 686-880 kg/da, 2013 yllında verim 781- 1078 kg/da, 2014 yllında verim 477- 991 kg/da, 2015 yılında 725-1855 kg/da arasında değișmiștir. 4 yllın ortalama verimleri 667-1198 kg/da arasında değișmiștir. S1 konusu 667 kg/ da en düșük, S4 konusu 1198 kg/da en yüksek verim vermiștir. Her 4 yılda S4 (21 gün) konusu en yüksek verimle birinci grupta yer almıștır. S4 konusunda ortalama sulama suyu 749 mm, su tüketimi 834 mm olmuștur.

Araștırmadan elde edilen veriler
değerlendirildiğinde Șanlıurfa koșullarında
zeytin yetiștiriciliğinde; zeytin hep yeșil bir bitki
olduğundan, bütün yıl boyunca su tüketir. Yüksek
verim için $600-800$ mm lik yağıșa intiyaç vardır.
Zeytinin su gereksinimine en çok duyduğu zaman
yaz aylarıdır. Yüksek verim için, bitkinin çekirdek
sertleșmesi așamasından bașlayarak meyve
olușumu așamasının sonuna kadar olan periyot
içinde suya gereksinim vardır. Yani zeytinin suya

en duyarlı olduğu zaman çiçeklenme ve çekirdek sertleșmesi așamalarıdır. Nitekim yapılan çalıșmalar bunları desteklemektedir. Zeytinin aktif gelișme periyodu boyunca uygulanan yeterli bir sulama programı periyodisiteyi azaltma eğilimindedir. Sulama suyunun kıt olduğu koșullarda, daha küçük bir ekim alanının su gereksinimini en üst düzeyde karșılamak yerine, kısıtlı su uygulamasına gidilerek su kaynağını daha geniș bir alandaki bitkilerin sulanmasına yöneltmek ve böylece toplam üretimi artırmak tercih edilmelidir.

\section{KAYNAKLAR}

Anonim (2010). www.gemlikzeytini.net. gov.tr.

Anonim (2016). Meteoroloji Genel Müdürlüğü. mgm.

Andria R, Morellı G (2002). Irrıgatıon Regıme Affects Yıeld And Oil Quality Of Olıve Trees. Iv International Symposium On Olive Growing (30 October 2002). Ed. C. Vitagliano, G.P. Martelli. Acta Hort. 586, Italy. Vol. 2.

Dinç U, Șenol S, Sayın M, Kapur S, Güzel N, Derici R, Yeșilsoy MȘ, Yeğingil I, Sarı M, Kaya Z, Aydın M, Kettaș F, Berkman A, Çolak A K Yılmaz, K, Tunçgögüs B, Çavușgil V, Özbek H, Gülüt KY, Karaman C, Dinç O, Öztürk N, Kara EE (1988). Güneydoğu Anadolu Bölgesi Toprakları (Gat). I. Harran Ovası.

Faci JM, Berenguer MJ, Espada JL, And Gracia S (2002). Effect Of Variable Water Irrigation Supply In Olive (Olea Europaea L.) Cv. Arbequina In Aragon (Spaın). Extra Virgin Oil Quality Parameters. Iv International Symposium On Olive Growing (30 October 2002). Ed. C.Vitagliano, G.P Martelli. Acta Hort. 586, Italy. Vol. 2.

Romero MP, Tovar MJ, Motilva MJ, Luna M, Girona J (2002). Effect Of Irrigation Strategies Applied On Olive Tree (Olea Europaea L.) On Oil Pigment Content And Colour. IV International Symposium On Olive Growing (30 October 2002). Ed. C. Vitagliano, G.P. Martelli. Acta Hort. 586, Italy. Vol. 2.

Tüzüner A (1990). Toprak Ve Su Analiz Laboratuvarları El Kitabı. Köy Hizmetleri Genel Müdürlüğü, Ankara. 